\title{
Ayrışmış Kaya-Zemin Ortamda Derin Kazı Uygulaması
}

\author{
${ }^{1}$ Aşkın Özocak, ${ }^{1}$ Ertan Bol ve ${ }^{* 1}$ Sedat Sert \\ ${ }^{* 1}$ Faculty of Engineering, Department of Civil Engineering, Geotechnical Lab., Sakarya University, Turkey
}

\section{Özet}

Gelişen teknoloji ve artan arazi fiyatları sonucu son yıllarda özellikle şehir merkezlerinde nitelikli ve yüksek yapılaşma talebi artmış ve bunun sonucunda derin kazı uygulamalarına sıkça ihtiyaç duyulur hale gelinmiştir. Ancak bununla birlikte özensiz ve ehil olmayan eller tarafindan yürütülen uygulamalar esnasında can ve mal kayıplarıyla sonuçlanan çalışmalar da dikkat çekmeye başlamıştır. Kaya ve özellikle zemin olarak tariflenen gereç diğer birçok mühendislik gerecine benzemez davranış sergileyebilmektedir. Bu durum özellikle derin kazı gibi hem kısa vade hem de uzun vadede farklı kayma direnci parametrelerinin uyanabildiği zemin ve kaya ortamlar için ilave bir özen ve tecrübe gereksinimi doğurmaktadır. Bu çalışmada Sakarya ilinde inşası planlanan yapı öncesi gerekli derin kazı çalışması için gerçekleştirilen saha çalışması, laboratuvar çalışması ve buradan elde edilen verilerin kullanımı ile yapılan analiz ve değerlendirmeler sonucu ortaya çıkan boyutlandırma uygulamasindan bahsedilmektedir.

Anahtar kelimeler: Derin kazı destek sistemi, zemin mekaniği, kaya mekaniği, şev stabilitesi

\begin{abstract}
As a result of developing technology and increasing land prices, high quality and high construction demand has increased especially in city centers. As a result, deep excavation applications are often required. However, it started to attract attention in the studies which resulted in loss of life and property during the practices carried out by the sloppy and unqualified hands. The material described as rock and especially soil can exhibit different behavior then many other engineering materials. This situation requires additional care and experience for the soil and rock environments where especially the deep excavation is able to mobilize the parameters of different shear resistance in both short and long term. In this study, the analysis and evaluations, which are carried out for a deep excavation work to be constructed in Sakarya, are mentioned by using the data obtained from field study and laboratory work.
\end{abstract}

Key words: Deep excavation support system, soil mechanics, rock mechanics, slope stability

\section{Giriş}

Ülkemizde son yıllarda özellikle şehir merkezlerinde artan nitelikli ve yüksek yapılaşma talebi nedeniyle derin kazı uygulamalarında artış göze çarpmaktadır. Bununla birlikte özensiz ve ehil olmayan eller tarafindan yürütülen uygulamalar esnasında can ve mal kayıplarıyla sonuçlanan çalışmalar da dikkat çekmeye başlamıştır. Zemin Mekaniği, Kaya Mekaniği ve Temel Mühendisliği başlıklarını kapsayan Geoteknik Mühendisliği’ni ilginç, renkli ve bir o kadar da hassas yapan sebeplerden birisi kaya ve özellikle zemin olarak tariflenen gerecin oluşum ve sonrasında maruz kaldığı değişken koşullar nedeniyle özellikleri ve davranışı açısından diğer birçok mühendislik gerecine benzemez oluşudur. Bu durum özellikle derin kazı gibi hem kısa vade hem de uzun vadede farklı kayma direnci parametrelerinin uyanabildiği zemin ve kaya

*Corresponding author: Address: Faculty of Engineering, Department of Civil Engineering Sakarya University, 54187, Sakarya TURKEY. E-mail address: ozocak@sakarya.edu.tr, Phone: +902642955738 
ortamlar için ilave bir özen ve tecrübe gereksinimi doğurmaktadır [1, 2]. Son y1llarda derin kazıların analizinde Plaxis vb. gibi yazılımlar çoğunlukla kullanılmakta, bu analizlerde de kısa ve uzun vade için zemin parametrelerinin seçimi önem kazanmaktadır [3]. Buna ek olarak zeminin drenaj durumu da sonuçları etkileyen önemli bir parametre olarak karşımıza çıkmaktadır [4].

\section{Materyal ve Metot}

$\mathrm{Bu}$ çalışmada Sakarya ilinde inşası planlanan yapı öncesi gerekli derin kazı çalışması için gerçekleştirilen saha çalışması, laboratuvar çalışması ve buradan elde edilen verilerin kullanımı ile yapılan analiz ve değerlendirmeler sonucu ortaya çıkan boyutlandırma uygulamasından bahsedilmektedir.

Çalışma alanı Akova üzerinde yer alan Adapazarı kent merkezinin batısında tepelik kısım üzerinde kalmaktadır [5]. İnceleme alanında görülen volkanik kökenli kumtaşlarının Alt-Orta Eosen yaşlı Çaycuma Formasyonunun Yığglca üyesine ait olduğuna karar verilmiştir (Şekil 1).

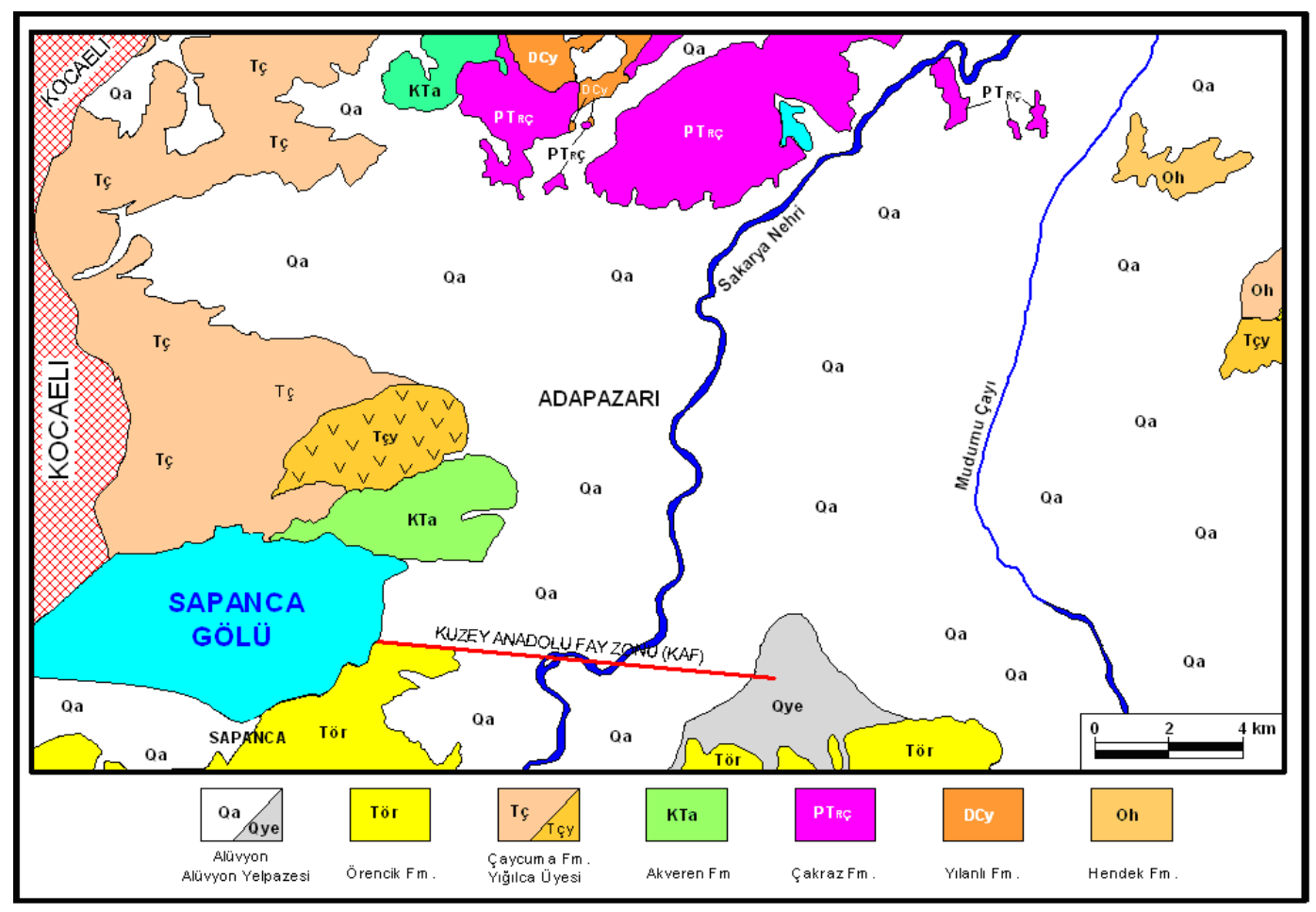

Şekil 1. Adapazarı ve çevresinin jeoloji haritası [5]

Tersiyer (Eosen) yaşlı Çaycuma Formasyonu (Tç) (MTA 2002' ye göre=Teç), Kazımpaşa beldesi ve çevresinde geniş alanlarda mostra verir. Kumtaşı, çamurtaşı, marn, nummulitli kireçtaşı, volkano klastik çakıltaşlarından oluşan bu birim sarı, gri, grimsi yeşil renklerde, ince, orta ve daha az kalın tabakalıdır. Eosen yaşı Yığılca Üyesi (Tçy), Sakarya Üniversitesi kampüsünün kuzeyindeki tepelerde, Selahiye ve Kırcali köyleri arasında mostra verir. Bu üye; andezit, bazalt, 
andezitik ve bazaltik lav, sinerit ve aglomera gibi kayaçlardan oluşur. Yer yer yastık (pilov) lav yapısı göstermektedir.

İnşası planlanan yapı bodrum katı yaklaşık $3.150 \mathrm{~m}^{2}$ oturma alanına sahip $3 \mathrm{~B}+\mathrm{Z}+2 \mathrm{~N}$ katlı olarak tasarlanmaktadır. Ortalama $90 \mathrm{~m} \times 35 \mathrm{~m}$ boyutlara sahip binanın maximum temel gömme derinliği $\left(D_{f}\right) 12.00$ metre ve temel sistemi de yayılı (radye) temel olarak düşünülmektedir. Yapının oturacağı alan birinci derece deprem bölgesinde kalmakta olup bölge 10 ile 30 yıl aralıklarla büyük depremlere maruz kalmaktadır [5].

Çalışma alanında inşası planlanan yapı için; zemin özelliklerinin belirlenmesi, temel boyutlandırması ve derin kazı analizine yönelik olarak 2017 yılında toplam derinliği 90 metre olan 6 adet karotlu sondaj, 2018 y1lında ise toplam derinliği $80 \mathrm{~m}$ olan 4 adet karotlu sondaj yaptırılmıştır. Sondaj yerlerini de içeren vaziyet planı Şekil 2'de verilmiştir. Sondaj logu verilerine göre çalışma alanında SK-1 ve 2 nolu sondaj kuyularında bitkisel toprak kalınlığından sonra çatlaklı çok ayrışmış kumtaşı birimine girilmekte ve kuyu sonuna kadar bu birim devam etmektedir. SK-3-4-5 ve 6 nolu kuyularda ise kalınlığ1 3.00 ile 4.50 metre arasında değişen dolgu tabakası kesilmiştir. Dolgu tabakasından sonra çatlaklı çok ayrışmış kumtaşı birimi devam etmektedir. Özetle, çalışma alanındaki zemin profili nebati toprak ve değişken kalınlıklı dolgudan sonra çatlaklı çok ayrışmış birimlerinden oluşmaktadır. Alanda yapılan sondaj çalışmalarında yeraltı su düzeyi rapor edilmemiştir

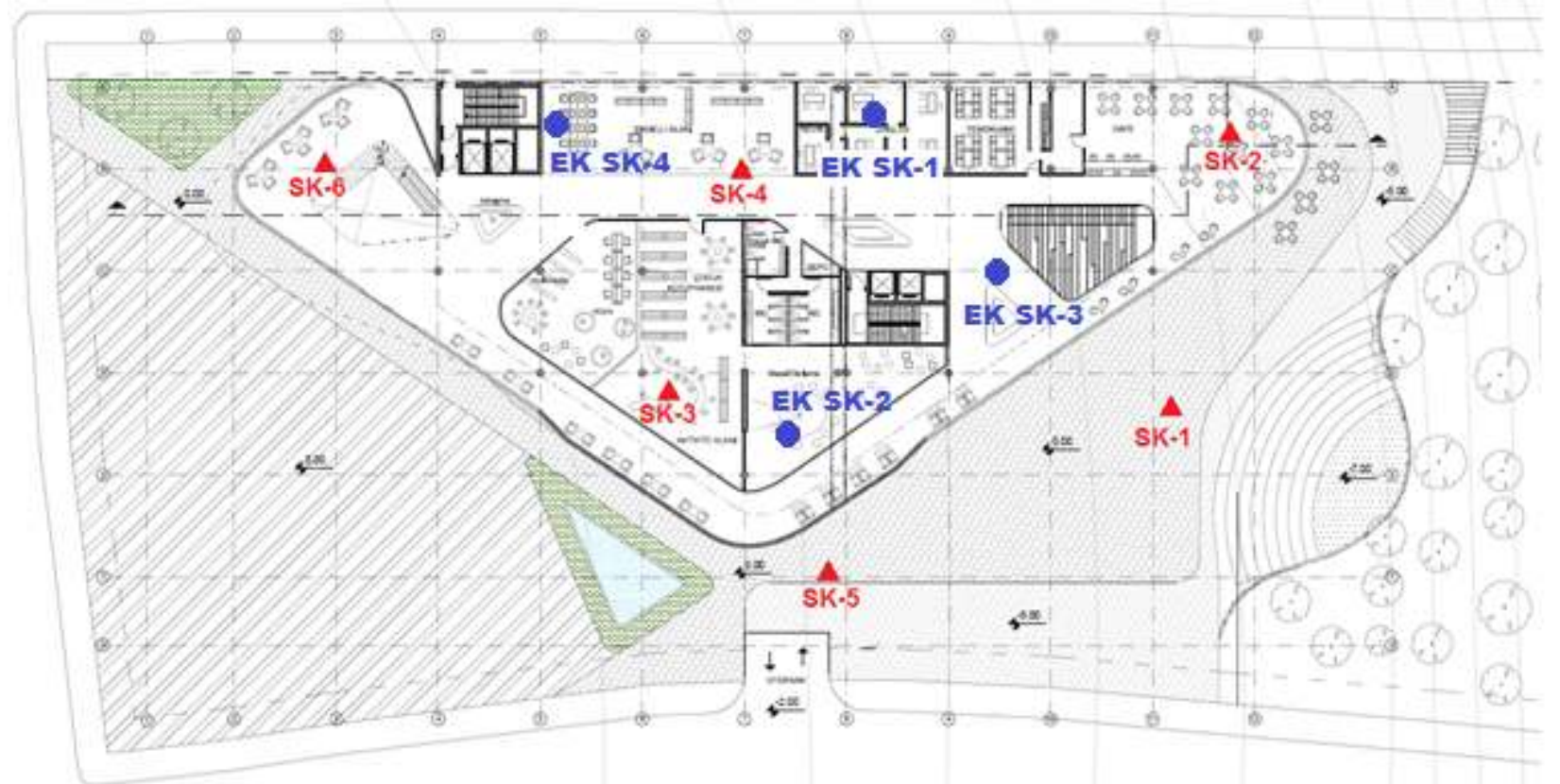

Şekil 2. Sondaj yerlerini de içeren vaziyet planı

\subsection{Laboratuvar çalışmaları}

Araziden alınan numuneler Sakarya Üniversitesi Geoteknik Laboratuvarında deneysel incelemeye tabi tutulmuşlardır. Çalışma alanında gerçekleştirilen birinci etap sondaj 
çalışmalarında laboratuvar çalışması için kayda değer bir numune almak mümkün olmamıştır. Alınan numuneler üzerinde sadece nokta yükleme deneyi uygulamak mümkün olmuş ve temel gömme derinliğinde kiltaşı biriminde $38 \mathrm{MPa}$ serbest basma dayanımı değerine ulaşılmıştır. İkinci grup sondaj çalışmasından gelen karot sandıklarından alınan ayrışmış kırıntılı numuneler üzerinde zemin sınıflandırma deneyleri yapılmış ve sonuçları Tablo 1'de verilmiştir.

Tablo 1. Çalışma alanı zemin özellikleri

\begin{tabular}{ccccccccccccc}
\hline Sondaj No & Derinlik $(\mathrm{m})$ & Renk & $\mathrm{w}_{\mathrm{n}}$ & $\mathrm{w}_{\mathrm{L}}$ & $\mathrm{w}_{\mathrm{P}}$ & PI & $\mathrm{I}_{\mathrm{L}}$ & Sınıf & $\% \mathrm{G}$ & $\% \mathrm{~S}$ & $\mathrm{FC}$ & Açık Adı \\
\hline EK SK-2 & 3.00 & SkK & 14 & 31 & NP & NP & --- & SM & 14 & 61 & 25 & Siltli Kum \\
EK SK-2 & 4.50 & SK & 14 & 29 & NP & NP & --- & SM & 13 & 63 & 24 & Siltli Kum \\
EK SK-3 & 3.00 & YKG & 14 & 33 & 22 & 11 & -0.74 & GC & 34 & 34 & 32 & Killi Çakıl ve Az Kum \\
EK SK-3 & 4.50 & kK & 15 & 37 & 24 & 13 & -0.74 & GC & 58 & 26 & 16 & Killi Çakıl ve Az Kum \\
\hline \multicolumn{8}{c}{ K: Kahve, S: Sarıms1, G: Gri, k: koyu, a: Açı } & &
\end{tabular}

Laboratuvara gelen ikinci grup numuneler üzerinde yapılan nokta yükleme deneyi sonuçları Tablo 2'de verilmiştir. Buna göre söz konusu deneyde tek eksenli basma dayanımı $\left(\sigma_{\mathrm{c}}\right)$ dolaylı olarak 8-18 MPa arasında bulunmuştur.

Tablo 2. Çalışma alanı nokta yükleme deney sonuçlarının değerlendirilmesi

\begin{tabular}{ccccccc}
\hline Sondaj No & Derinlik $(\mathrm{m})$ & Çap $(\mathrm{mm})$ & Yük $(\mathrm{kN})$ & $\mathrm{F}$ & $\mathrm{Is}_{(50)}(\mathrm{MPa})$ & $\sigma_{\mathrm{c}}(\mathrm{MPa})$ \\
\hline EK SK-1 & 7.50 & 61.10 & 2.50 & 1.094 & 0.733 & 17.59 \\
EK SK-1 & 12.00 & 60.50 & 1.10 & 1.090 & 0.327 & 7.86 \\
\hline
\end{tabular}

Bununla birlikte karot sandıklarından gelen kumlu birimler üzerinde kesme kutusu deneyleri yapılmış ve sonuçları Tablo 3'de verilmiştir. Kesme kutusuna numuneler yerleştirilmeden önce 4 mm elekten elenmiş ve sıkıştırılmıştır.

Tablo 3. Çalışma alanı zeminleri kesme kutusu deney sonuçları

\begin{tabular}{cclccccc}
\hline Sondaj No & Derinlik $(\mathrm{m})$ & Renk & $\mathrm{w}_{\mathrm{n}}(\%)$ & $\mathrm{e}$ & $\rho\left(\mathrm{kN} / \mathrm{m}^{3}\right)$ & $\mathrm{c}(\mathrm{kPa})$ & $\phi\left({ }^{\mathrm{o}}\right)$ \\
\hline EK SK-3 & 6.50 & $\mathrm{kG}$ & 23 & 0.83 & 17.62 & 0 & 38 \\
EK SK-3 & 17.00 & $\mathrm{SkK}$ & 13.5 & 0.38 & 21.50 & 0 & 55 \\
\hline \multicolumn{7}{c}{ K: Kahve, S: Sarımsı, G: Gri, k: koyu }
\end{tabular}

\section{Kazı Güvenliği ve Gerekli Önlemlerin Değerlendirilmesi}

Çalışma alanında temel inşası $12.60 \mathrm{~m}$ derinliğine varan kazı çalışması öngörülmektedir. Çevre ve Şehircilik Bakanlığı tarafından 2018 yılında yayınlanan "Kazı Çukurlarının Desteklenmesi ile İlgili Uyulacak Esaslar" genelgesinde ortalama insan boyuna karşılık gelen 1.75 m'yi aşan kazı derinliklerinde kazı güvenliğinin analiz edilmesi gerektiği belirtilmektedir [6]. Çatlaklı çok ayrışmış kumtaşı olarak tariflenmiş hâkim temel ortamında yapılan sondaj çalışmalarından gelen kırıntılı numuneler üzerinde yeniden yerleştirme ile yapılan kesme kutusu deneyleri sonrasında numunelerde kohezyon olmadığı bulunsa da sondaj sırasında bağlayıcı maddenin yıkandığı ve zemin sınıflandırmalarından da ortamın yer yer kil içerdiği göz önüne alınırsa $10 \mathrm{kPa}$ civarında bir kohezyon değerinin stabilite hesaplarında kullanılabileceği düşünülmüştür. 
Bununla birlikte kayma direnci açısı 38-55 gibi yüksek düzeylerde kendini göstermiş, bu durumda da güvenli tarafta kalınarak 35 derecelik bir kayma direnci açısı stabilite hesaplarında kullanılmak üzere seçilmiştir.

\subsection{Stabilite Analizleri}

Sondaj çalışmaları sonucunda arazide yer altı su seviyesi rapor edilmediğinden modellerde yeraltı suyu girilmemiştir. Stabilite analizlerinde üst dolgu tabakası için $c=10 \mathrm{kPa}$ ve $\phi=32^{0}$ olarak alınmıştır. Altta bulunan çok ayrışmış kumtaşları için $c=10 \mathrm{kPa}$ ve $\phi=35^{\circ}$ alınmasının uygun olacağı düşünülmüştür.

$\mathrm{Bu}$ durumda çalışma alanının güney batı köşesinde bulunan karakol binası sebebi ile şevli kazı şansının olmadığı yerde dik bir kazı gerçekleştirilmesi söz konusudur. Bu kesitte durumu ortaya koyabilmek için kazık ve ankraj varlığını dikkate alabilen Talren yazılımı ile stabilite analizleri yapılmıştır. Kazıksız ilk çözüm Şekil 3'de görülmektedir. Güvenlik sayısı 0.53 (GS<1.00) civarında çıkmıştır. Buradan anlaşılacağı üzere ortamda desteksiz bir dik kazının yapılması mümkün değildir.

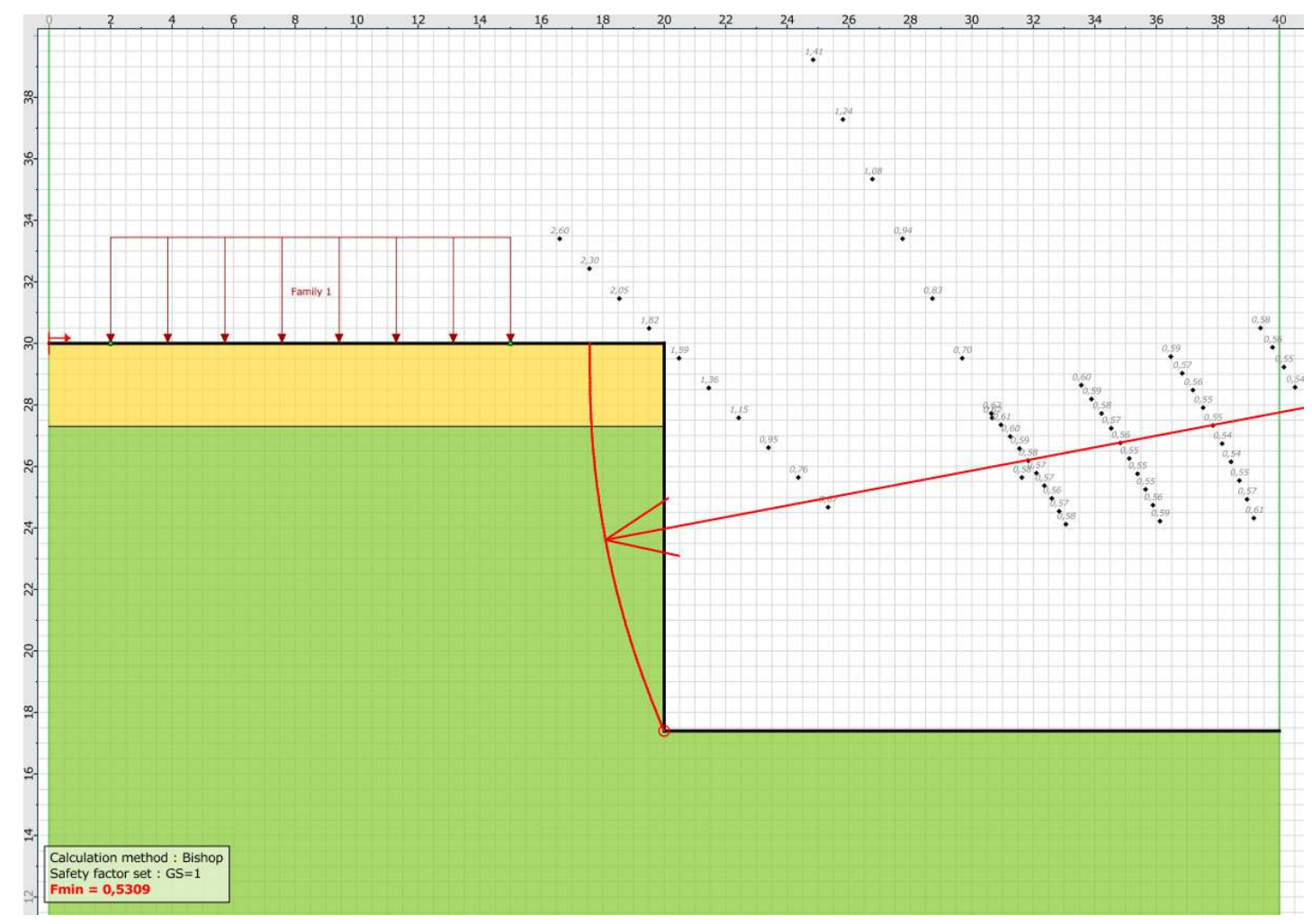

Şekil 3. Çalışma alanı güney batı köşesinde desteksiz kazı stabilite analizi sonucu

Bu durumda uzunluğu 16 metre ve çapı $60 \mathrm{~cm}$ olan teğet kazık uygulaması ile analiz tekrarlanmış ve sonucu Şekil 4'te sunulmuştur. Güvenlik sayısının 0.95 çıkması sadece $60 \mathrm{~cm}$ çaplı kazık uygulamasının da yeterli olmayacağına işaret etmiştir. 


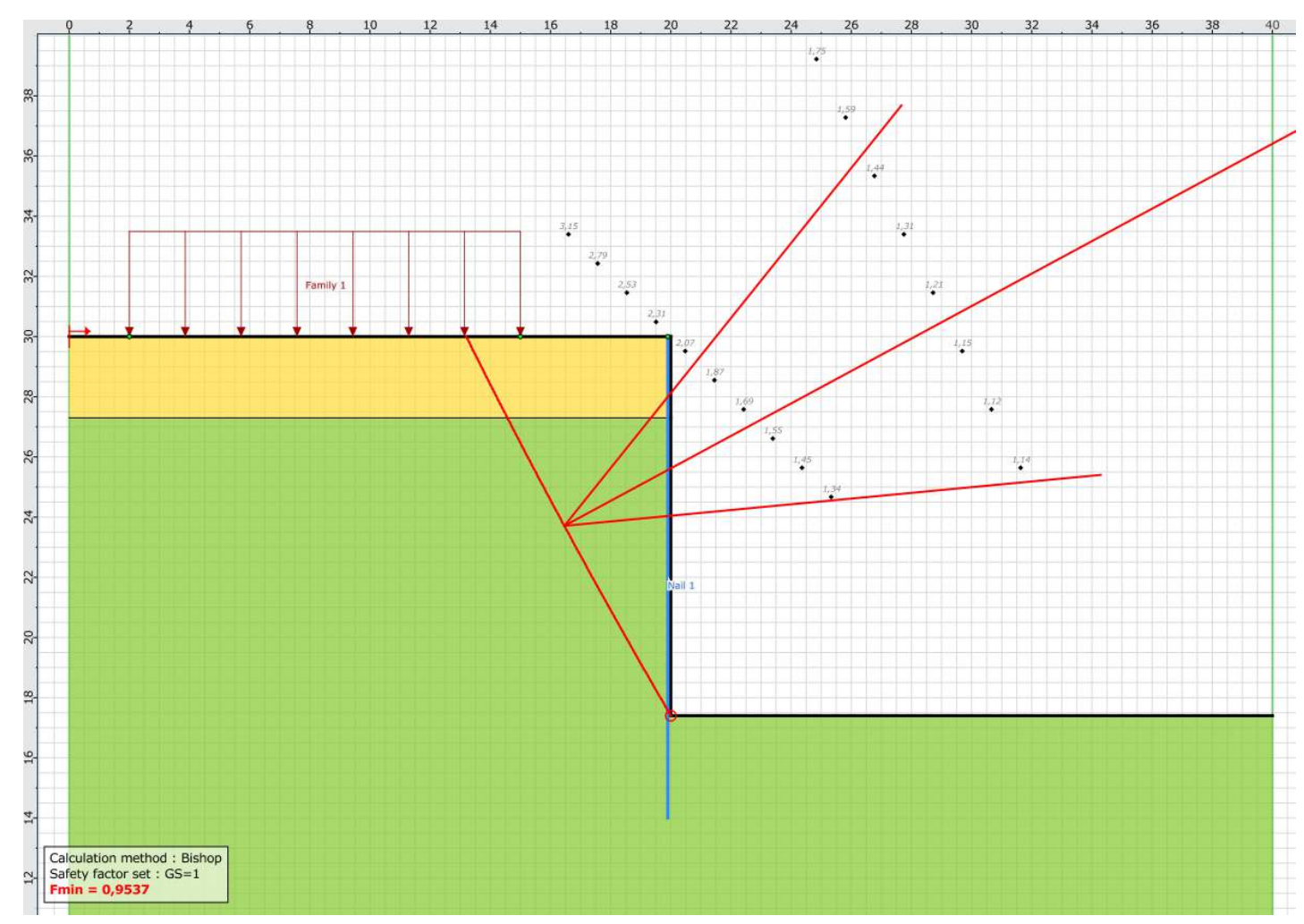

Şekil 4. Çalışma alanı güney batı köşesi teğet kazıklı stabilite analizi sonucu

Bu durumda yatayda 3 metre aralıklı olmak üzere tek ve iki sıra ankraj uygulaması ile analizler tekrarlanmıştır. Tek sıra ankrajlı çözüm Şekil 5'te, çift sıra ankrajlı çözüm Şekil 6'da verilmiştir. Tek sıra ankrajlı durumda güvenlik sayısı 1.09 civarlarında iken çift sıra ankrajlı durumda güvenlik sayısının 1.22 düzeylerine çıktığı anlaşılmaktadır. Tüm ankrajlar $350 \mathrm{kN}$ (35 ton) kapasiteli olarak hesaplamalara katılmıştır. İlk sıra ankraj yatayda $3.00 \mathrm{~m}$ aralıklı olup, 7.00 metre kök boyu ve 5.00 metre serbest boya sahip olmak üzere 12.00 metre toplam uzunluğundadır. İkinci sıra ankrajlar ise yatayda $3.00 \mathrm{~m}$ aralıklı olup, 5.00 metre kök boyu ve 4.00 metre serbest boya sahip olmak üzere 9.00 metre toplam uzunluğundadır.

Kazı alanının diğer kesimlerinde idare şevli kazı yapacak yeterli alanın olduğunu beyan etmektedir. Bu durumda en yüksek kazı derinliği olan $12.00 \mathrm{~m}$ göz önüne alınarak şevlerin 3 düşey / 2 yatay eğimli oluşturulmasıyla yapılmış stabilite analizi sonucu Şekil 7'de verilmiştir. Bu hesaplamada palye genişliği 3 metre alınmış olup güvenlik sayısı en düşük 1.40 civarındadır. Şekil 7'de gösterilen hesaplamanın bir benzeri palye genişliğinin $2.00 \mathrm{~m}$ olması durumu için de tekrarlanmıştır (Şekil 8). Bu durumda da güvelik sayısı en düşük 1.24 civarındadır. 
A. ÖZOCAK ve diğ./ ISITES2018 Alanya - Antalya - Turkey

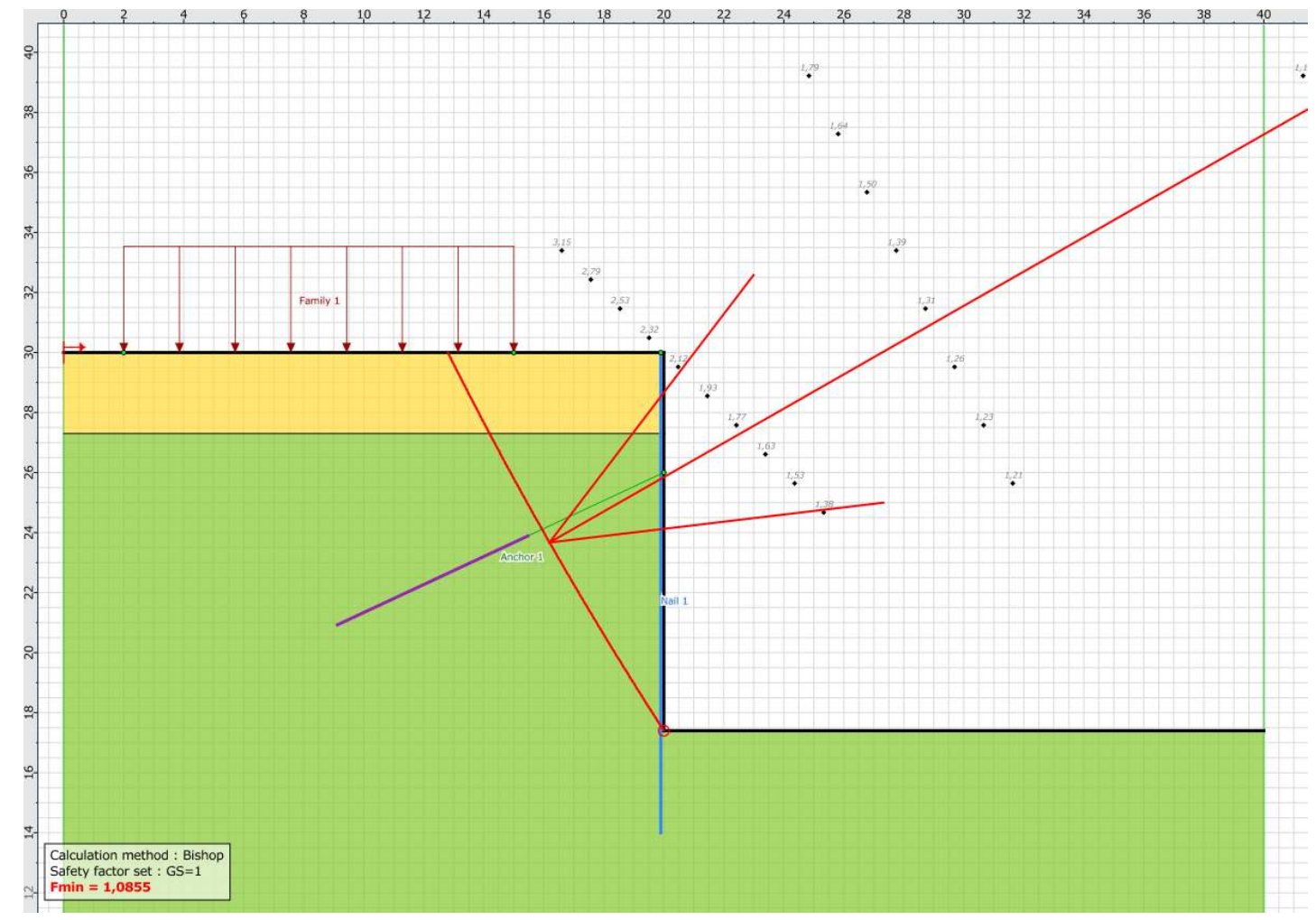

Şekil 5. Çalışma alanı güney batı köşesi kazık+tek sıra ankraj stabilite analizi sonucu

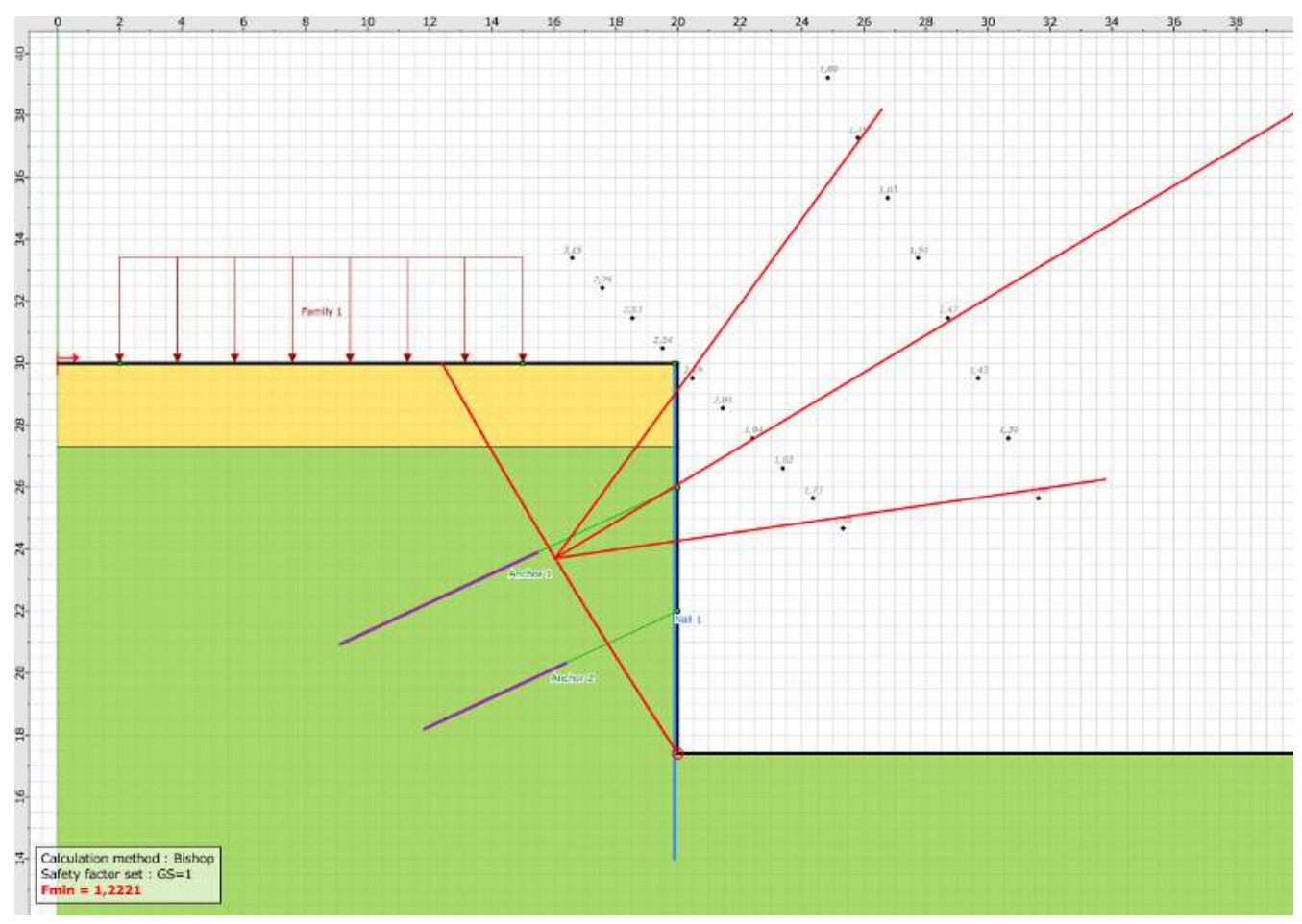

Şekil 6. Çalışma alanı güney batı köşesi kazık+çift sıra ankraj stabilite analizi sonucu 


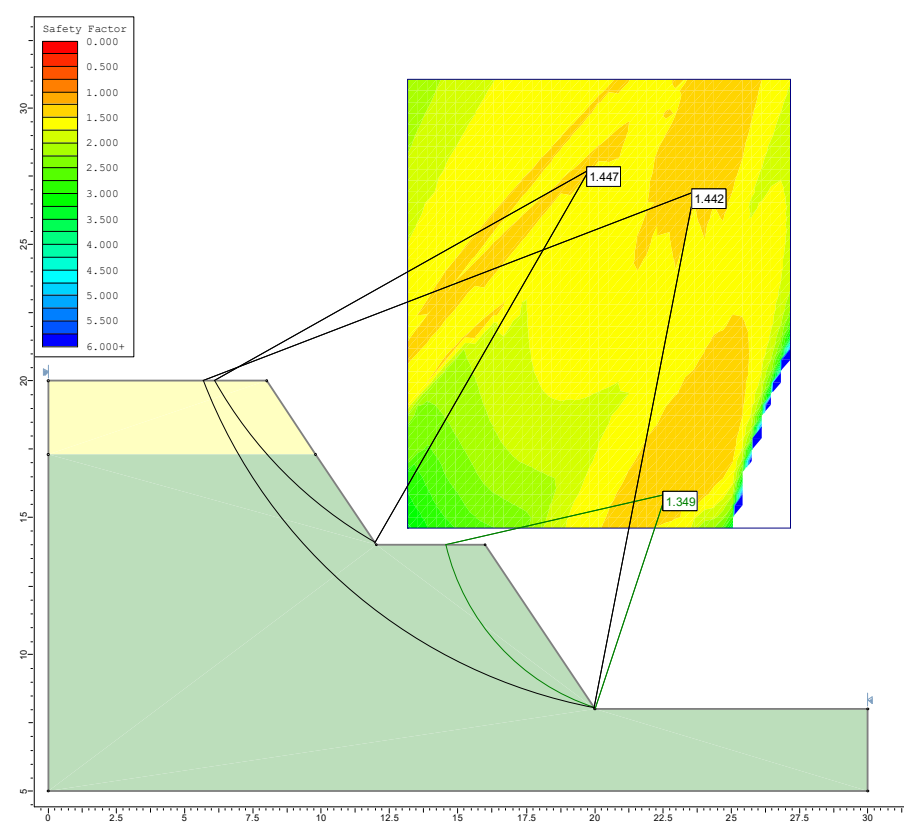

Şekil 7. Çalışma alanı 3D/2Y-3 m palyeli şevli kazı stabilite analizi

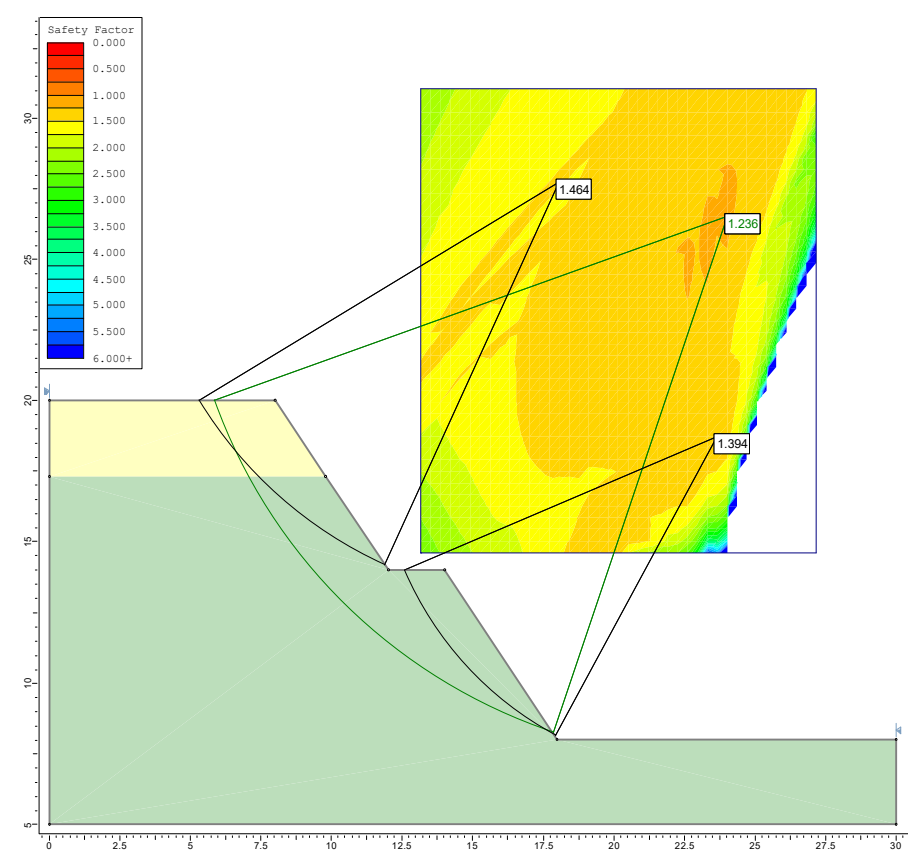

Şekil 8. Çalışma alanı 3D/2Y-2 m palyeli şevli kazı stabilite analizi

\subsection{Derin Kazı Analizleri}

$\mathrm{Bu}$ bölümde çalışma alanında en derin kazı derinliğine sahip olan kesitte, güney batı köşesinde mevcut binaya komşu noktada ReWard yazılımı kullanılarak derin kazı analizi yapılmıştır. Analizler konsol perde, tek ankrajlı ve çift ankrajlı alternatifler için tekrarlanmıştır. Bilindiği gibi ankraj uygulaması perde boyunu azalttı̆̆ gibi kesite gelecek olan maksimum moment 
büyüklüğünü de önemli derecede düşürmektedir. Analiz sonuçlarına göre komşu bina hizasında $12.60 \mathrm{~m}$ derinliğe ulaşacak olan kazının güvenliğini sağlayabilmek için $60 \mathrm{~cm}$ çapında ve $16 \mathrm{~m}$ boyunda teğet kazıklı perdenin inşa edilmesi ve bunun $4 \mathrm{~m}$ ve $8 \mathrm{~m}$ derinliklerde teşkil edilecek 2 sira halindeki, yatayda ise 3 'er $\mathrm{m}$ aralıklı, 45 ton kapasiteli ankrajlarla desteklenmesi gerekecektir. Şekil 9'da kazıklı perdenin çift sıra ankrajla desteklendiği modelde elde edilen sonuçlar gösterilmektedir.

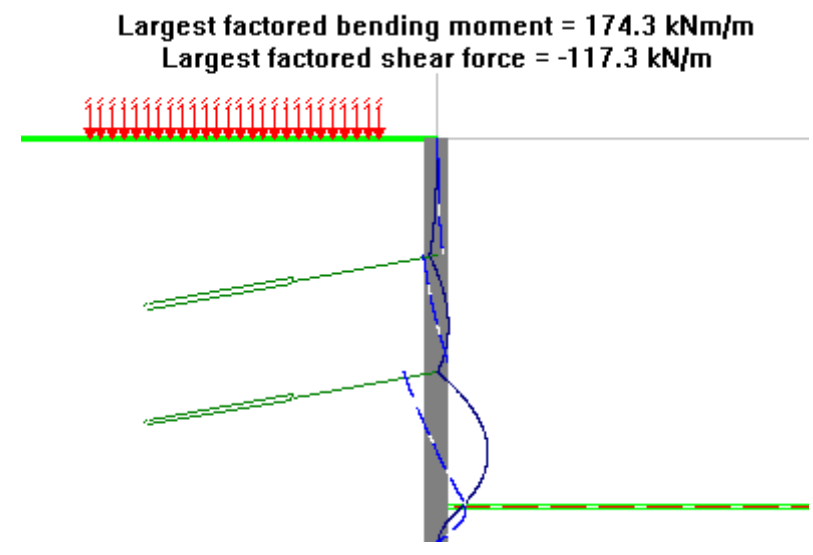

Şekil 9. Çift sıra ankrajlı kazıklı perde moment dağılımı

\section{Sonuç ve Öneriler}

Sakarya ilinde yer alan çalışma alanında inşası planlanan yapının derin kazısı ile ilgili olarak derin kazı kesitinin en kritik olduğu bölge güney batı sınırında komşu yapının bulunduğu bölgedir. Bu alanda kazı derinliği 12.60 m olarak verilmiştir. Şekil 10'da gösterilen sınırlar (mavi daireler) boyunca $60 \mathrm{~cm}$ çapında ve 16 boyunda, teğet kazıklı perdenin $4 \mathrm{~m}$ ve $8 \mathrm{~m}$ derinliklerde teşkil edilecek 2 sıra halindeki, yatayda ise 3'er $\mathrm{m}$ aralıklı 45 ton kapasiteli ankrajlarla desteklenmesi gerekmektedir. Yola bakan kısımlarda ise tüm diğer özellikler aynı olmak kaydı ile kazıklar merkezden merkeze $100 \mathrm{~cm}$ aralıklı olabilir (kırmızı daireler).

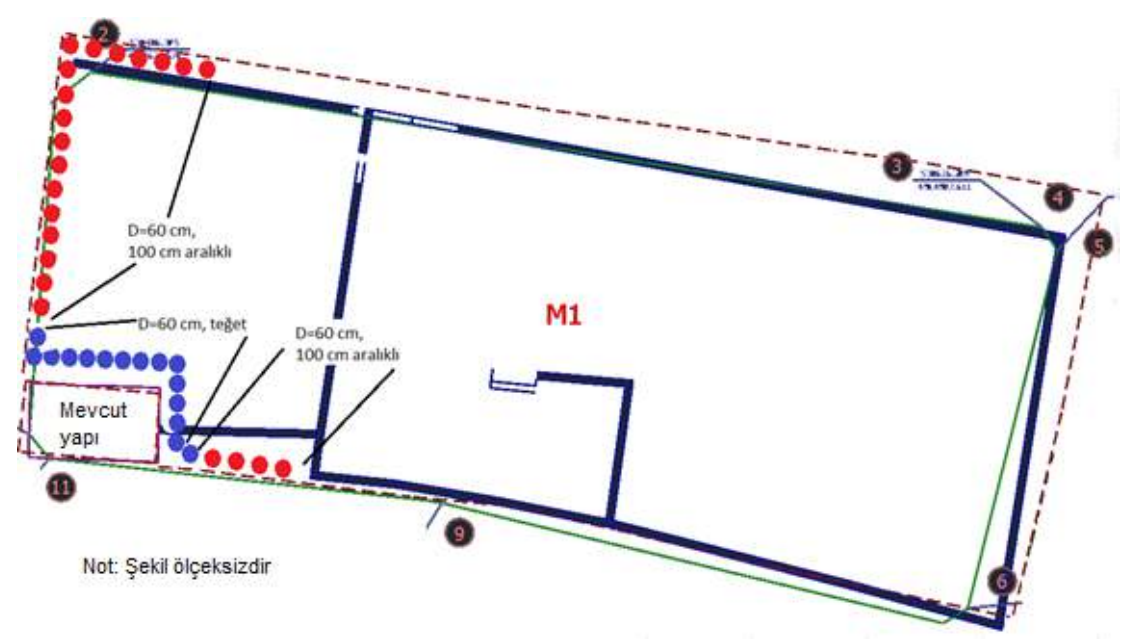

Şekil 10. Çift sıra ankrajı kazıklı perde yeri 
Bu bölgenin dışında kalan sınırlarda ise 3D / 2Y eğimli olmak üzere $3 \mathrm{~m}$ palye kullanılarak 2 kademeli kazı uygun olacaktır. Bunun yanında kazı sırasında ön inceleme sirasında öngörülemeyen zayıflık zonları ile karşılaşılabilir. Bu durumda yüzeysel akmaları önlemek amacı ile ilgili yüzeylere $5 \mathrm{~cm}$ püskürtme beton uygulaması tavsiye edilir. Kazı sürecinde parsel etrafındaki taşı ve yaya yollarında güvenlikle ilgili önlemlerin alınması gerekmektedir. Söz konusu kazı çalışmasının yağışsız mevsimde yapılması çok önemlidir. Ayrıca inşaat sürecinde olası yağışlara karşı kazı alanına yüzeysel suların yönlenmemesi için kazı etrafında kafa hendeği vb. bir tasarım ile drenajın sağlanması gerekmektedir.

Son yıllarda hızla artan derin kazı çalışmalarında görülen kazalardan anlaşılacağı gibi diğer mühendislik malzemelerine benzemez davranışlar gösterebilen zemin-kaya ortamlarda yapılacak analiz ve boyutlandırma için ehil olmayan ellerin yapacağı uygulamalardan kaçınılmalıdır.

\section{Kaynaklar}

[1] Özocak A, Sert S, Bol E. A case study: stability problem of a retaining wall. $3^{\text {rd }}$ International Symp. on Innovative Technologies in Engineering and Science, Universidad Politécnica de Valencia, 2015.

[2] Bol E, Sert S, Özocak A. Slope design for excavations and embankments for a waste deposit area. $3^{\text {rd }}$ International Conference on Engineering and Natural Science, Budapest, Hungary, 2017.

[3] Aktaş T, Çalışan O, Çokça E. Ankara kilinde $18.5 \mathrm{~m}$ derinliğindeki bir kazının geri analizi: örnek olay incelemesi. Zemin Mekaniği ve Geoteknik Mühendisliği 17. Ulusal Konferans1, İstanbul Üniversitesi, İstanbul, 2018.

[4] Tonaroğlu M. Bir kazı stabilitesi üzerinde drenajl1/drenajsız durum etkisi. Zemin Mekaniği ve Geoteknik Mühendisliği 17. Ulusal Konferansı, İstanbul Üniversitesi, İstanbul, 2018.

[5] Sarıaslan MM, Yurdakul ME, Osman ÇR, Keçer M, Basa F, Şentürk K. Sakarya ilinin çevre jeolojisi ve doğal kaynakları, MTA Raporu, No. 10195, 1998.

[6] Çevre ve Şehircilik Bakanlığı Genelgesi. Kazı Çukurlarının Desteklenmesi ile İlgili Uyulacak Esaslar. Ankara, 2018. 